\title{
Onde Falta Melhorar a Pesquisa em Psicologia no Brasil sob a Ótica de Carolina Martuscelli Bori
}

\author{
Sílvio Paulo Botomé ${ }^{1}$ \\ Universidade Federal de Santa Catarina
}

\begin{abstract}
RESUMO - É preciso considerar que a pesquisa neste país se faz em um contexto típico de Terceiro Mundo. As reivindicações da comunidade científica nacional têm enfatizado a necessidade de participar nas decisões que definem e orientam a atividade de pesquisa. Escolher a atividade de pesquisa e seu objeto alvo é responsabilidade coletiva dos cientistas do País. O cientista precisa aprender a falar para as pessoas dos mais diferentes segmentos da população. A Universidade é a agência onde essas condições podem ocorrer e é uma instituição que necessita ser defendida, retomada e reorientada para seu papel maior: produzir o conhecimento que o Brasil necessita e torná-lo acessível - pela divulgação e pelo seu uso no ensino - à população do País. Política científica em Psicologia não se fará sem a participação dos cientistas e das universidades. Instrumentos, atividades e instituições necessitam ser apropriados à proposta de participação coletiva dos cientistas de forma que a pesquisa em Psicologia seja um empreendimento real, significativo, coletivo e emancipador.
\end{abstract}

Palavras-chave: política científica em psicologia; organização política em ciência; política científica; função social da psicologia como ciência.

\section{Where Psychology Research in Brazil Needs to be Improved under Carolina Martuscelli Bori Point of View}

\begin{abstract}
SUMMARY - It is necessary to consider that research in this country is made under a typical context of the Third World. The claims of the national scientific community have emphasized the need to participate in the decisions that define and guide the research activity. To choose the research activity and its main object is a collective responsibility of the scientists of this Country. The scientist needs to learn how to speak with people from the most different segments of the population. The University is the agency where these conditions may occur and it is an institution that needs to be defended, resumed and reoriented to its major role: to produce the knowledge that Brazil needs and turn it accessible - by disclosure and by its use in education - to the population of the Country. Scientific policy in Psychology will not be made without the participation of the scientists and the universities. Instruments, activities and institutions need to be fitted to the proposal of collective participation of the scientists so that the research in Psychology be a real, significant, collective and emancipating enterprise.
\end{abstract}

Key words: scientific policy in psychology; political organization in science; scientific policy; social function of psychology as a science.

Quinze anos antes de terminar o século XX, a professora Carolina Martuscelli Bori participou de um debate com outros dois cientistas da Psicologia na Universidade de Brasília (UnB) como parte da mesa redonda sobre "A pesquisa no Brasil; problemas e soluções", em um seminário acadêmico ocorrido em outubro de 1984. O debate iniciado pelos demais expositores enfatizou dimensões técnicas, destacando os tipos de pesquisa, os problemas metodológicos, as dificuldades para aumentar o volume de pesquisa ou para sua inserção no ensino regular como uma parcela importante e constante na formação de novos psicólogos. Pela formação dos participantes, o debate esteve focalizado no que acontecia mais centradamente na formação em Análise Experimental do Comportamento. À medida que as exposições e o debate prosseguiam, ainda relativamente às exposições dos dois participantes que o iniciaram, professora Carolina ficava nitidamente inquieta e fazia anotações em uma folha de pa-

1 Endereço: Universidade Federal de Santa Catarina, Departamento de Psicologia, Campus Universitário Trindade, Florianopolis, SC, Brasil 88040-900. Caixa-Postal: 476.E-mail: botome@ufsc.br pel. O que acontecia no debate parecia provocá-la. Quando falou, suas palavras constituíram uma torrencial explanação sobre a falta de um tipo de dimensão nas discussões sobre "fazer Ciência em Psicologia, especificamente em Análise do Comportamento". O que professora Carolina falou foi surpreendente e emocionou a platéia pelo tom, pela fundamentação, pela precisão de raciocínio, pela natureza das idéias e pelo envolvimento apaixonado com que apresentou as idéias sobre "o que falta fazer em Ciência na área da Psicologia no Brasil".

Por acaso, eu estava a menos de dois metros de professora Carolina Bori e acompanhei não só sua exposição, anotando tudo o que podia, como observei que uma estudante de Psicologia da UnB estava, com anuência de professora Carolina, gravando o que era dito. Alguns meses depois recebi uma cópia da fita. Fiquei emocionado com o que tinha nas mãos e ouvi aquela fita muitas vezes. Um aluno de mestrado transcreveu a gravação em um texto inicial e me possibilitou conferir a audição da fita com a leitura do texto também muitas vezes. 
Pedi a autorização de professora Carolina para editar o texto e, com sua anuência, trabalhei nisso algum tempo. Apresentei-o à professora Carolina que, depois de examinálo, disse ter gostado da edição. Professora Carolina ficou de pensar em qual periódico seria melhor publicá-lo, uma vez que o considerava de uma amplitude que não era apropriada para alguns tipos de periódicos e com aspectos que, por vários motivos, seriam considerados controvertidos em relação ao título que o trabalho recebera.

O tempo passou. Houve muitas tarefas e desencontros para resolver o acabamento da edição e o encaminhamento para publicação. O texto terminou sendo conhecido apenas por mim e por professora Carolina, com a sempre discreta participação de Deisy das Graças de Souza que acompanhou esse processo como amiga sempre próxima à professora $\mathrm{Ca}$ rolina e como uma colega de trabalho com quem repartimos muito as experiências de trabalho durante vários anos na Universidade Federal de São Carlos nos quais convivemos com professora Carolina.

Professora Carolina faleceu sem termos encaminhado a publicação desse texto, como estávamos planejando e combinando e, duas décadas depois, fico constrangido em tê-lo comigo, sem partilhar a riqueza que considero nele existente. Por outro lado, não me sinto à vontade em torná-lo público sem contextualizá-lo e esclarecer alguns aspectos da situação e da época em que ele foi apresentado pela primeira vez a uma audiência de estudantes, pesquisadores e professores na Universidade de Brasília, durante um seminário. A decisão sobre o que fazer foi auxiliada pela sugestão de uma colega: "escreva um texto apresentando a exposição de professora Carolina, tornando acessível as idéias que ela apresentou e examinou".

Este texto é uma tentativa de fazer isso, com todos os riscos e defeitos que possam acarretar, diante do fato de ser um ouvinte, um intérprete, um "arrumador" de expressões orais para um texto escrito e um organizador de um texto para ser publicado, com o agravante de não ser o autor das idéias expressas no texto. $\mathrm{O}$ único atenuante que posso utilizar é ter examinado tudo isso ao longo de vários anos com professora Carolina e ter discutido e examinado as idéias do texto em um total que passou de duas centenas de horas. Mesmo assim, assumo que os defeitos do texto tenham mais a ver com minhas limitações como escritor do que com as idéias sempre fortes e orientadoras de professora Carolina Martuscelli Bori. É essa convicção que me faz apresentar-lhes esse texto, como uma tentativa, talvez pobre demais para as expectativas de vocês, leitores, em relação ao que está escrito por um intermediário, apresentador e comentador de um texto dessa magnífica pessoa que foi e será sempre a nossa eterna professora Carolina.

O mesmo assunto permanece em debate: o que professora Carolina provocava na época ressurge, mais de 20 anos depois, com, por exemplo, as discussões promovidas na Reunião Anual da ABPMC de 2006, também em Brasília, sobre a representação, participação e organização dos analistas de comportamento na Psicologia e no Brasil. Duas décadas depois, as idéias e o exame de professora Carolina Martuscelli Bori parecem muito atuais. É o que faz valer a pena ler este texto e me faz apresentá-lo dessa forma à revista Psicologia: Teoria e Pesquisa para trazer a contribuição de professora
Carolina para o que permanece ou prossegue. Tenho a expectativa, talvez ingênua, de que o exame de 2007 possa ser enriquecido com o exame que tento lhes apresentar nessas próximas páginas. Este texto é, antes de tudo, uma homenagem e um reconhecimento em prolongar nossa conversa com ela, mesmo depois que ela já não nos pode responder como o fazia, com vigor, com rapidez, sem meias palavras com uma torrente que nos inundava de questões, perspectivas, possibilidades, desafios...

O texto a seguir apresenta o que professora Carolina expôs, com as arrumações textuais que me atrevi a fazer: arrumar pontuação, tirar repetições de termos, tirar referências específicas a pessoas e instituições, mudar expressões próprias de uma exposição oral pouco úteis para um texto e decisões sobre estrutura, início e fim de cada parágrafo. Sempre, obviamente, com o cuidado de não alterar o que eram as palavras de professora Carolina. Para auxiliar e destacar aspectos importantes, foi colocada, à esquerda de cada parágrafo da exposição de professora Carolina, uma frase que constitui, ao nosso ver, o núcleo do parágrafo à direita dessas frases.

Esperamos estar partilhando mais um pouco da riqueza que nossa sempre querida professora Carolina Martuscelli Bori sabia nos presentear com a força e a coragem de uma guerreira e a simplicidade e delicadeza de um anjo. Provavelmente, foi assim que muitos de nós a conhecemos e é como ela permanecerá em nossas lembranças.

Um desafio perene: integrar Pesquisa, Psicologia e Brasil. pesquisa científica, Psicologia e Por qual aspecto ou critério o que caracteriza o Brasil. relacionar a multiplicidade de variáveis que cada uma dessas expressões abrange? As infinitas possibilidades de fazê-lo não autorizam adiar as exigências de responsabilidade e o enfrentamento do desafio do momento: é necessário aumentar a percepção sobre os problemas que existem nas relações entre o que cada uma dessas três palavras abrange e significa.

É urgente avaliar no que, em Discutir sobre a pesquisa no que grau de abrangência ou de Brasil é um empreendimento que forma pode ser útil exami- louvável. Isso já vem ocorrennar a pesquisa em Psicologia do há algum tempo e em várias no Brasil. reuniões, encontros e congressos científicos. A manutenção do debate sobre esse tema é muito importante: é necessário haver uma grande familiaridade dos pesquisadores em relação ao que está acontecendo com o "pesquisador" no País. Essa discussão, porém, não pode ser feita de qualquer maneira, ou corre o risco de tornar-se "esquizofrênica" e irreal. Discutir em termos gerais não resolve nada ou é muito pouco. Conversar sobre aspectos específicos pode dar a impressão de que tudo está bem, de que é suficiente resolver uns poucos problemas e a pesquisa no País irá de "vento em popa". Afinal, existem muitos pesquisadores, há várias agências de fomento, existem recursos (embora possam aumentar) e as regras para participar de tudo isso já estão disponíveis, mesmo que ainda possam ser mais acessíveis e melhores. A necessidade do debate e as duas possibilidades 
de exame trazem a urgência de considerar uma questão: no que, em que grau de abrangência ou de que forma pode ser útil examinar a "pesquisa em Psicologia no Brasil”?

Os pesquisadores da Psicologia Talvez, mais do que discutir estão perdendo a possibilidade a pesquisa em Psicologia de acompanhar os debates $\boldsymbol{e}$ nas suas especificidades, decisões pela ausência no que seja importante examinar os define os destinos e caracterís- problemas da pesquisa no ticas da Ciência no País. Brasil. Discutir o "pesquisar em Psicologia" necessita ser precedido pelo exame das condições do "pesquisar" e para o trabalho de fazê-lo no País. Os aspectos envolvidos são numerosos em um e outro caso. Mesmo assim, parece valer a pena examinar algumas considerações sobre a participação da Psicologia nas discussões sobre a Ciência no Brasil. Talvez nessas discussões não esteja existindo a contribuição da Psicologia, perdendo, os pesquisadores dessa área, a possibilidade de acompanhar os debates e decisões, deixando de participar, com sua presença e sua voz, no que define os destinos e características da Ciência no País.

Só é possível equacionar "solu- Quando o problema da pesções” que sejam apropriadas ao quisa no Brasil é objeto de contexto de desenvolvimento da exame, o primeiro aspecto a Ciência e da Tecnologia desta considerar é que não é aprosociedade e apropriadas ao priado fazer esse exame sem desenvolvimento do País. localizá-lo no contexto de ser o Brasil um país do Terceiro Mundo. Esse exame, até 1970, vinha sendo feito por grupos pequenos e rarefeitos. Desde aquele ano, porém, isso foi se tornando cada vez mais voz corrente entre os pesquisadores brasileiros. Nesse sentido, a perspectiva de exame do problema precisa ser uma perspectiva brasileira. Só é possível equacionar "soluções" que sejam apropriadas ao contexto do desenvolvimento da Ciência e da Tecnologia deste meio. Da Ciência e Tecnologia apropriadas ao desenvolvimento deste País.

Antes de haver uma separação É preciso descobrir ou aprenpara discutir as condições da der, desde logo, que este País pesquisa em Psicologia, de- tem uma condição diferente vemos dizer o que precisa ser dos países já consagrados feito de pesquisa em Psicologia como produtores de Ciência no Brasil

e Tecnologia. E isso exige que, antes de haver uma separação para discutir as condições da pesquisa em Psicologia, devemos dizer o que precisa ser feito de pesquisa em Psicologia no Brasil. Para poder dizer isso, porém, é necessário ter um pouco mais claro o que está sendo reivindicado pela comunidade científica deste País. É uma comunidade que vive angustiada pelos problemas típicos do Terceiro Mundo. Nunca essa angústia foi tão perceptível como nos últimos anos. Nunca esteve tão presente no meio científico como está hoje. Ela vai se avolumando de uma forma tal que, se não for feita alguma coisa dentro do campo da Ciência e da Tecnologia no país, o Brasil - e cada um de nós! - vai perder... e por muitas dezenas de anos.
A grande quantidade do que Atualmente ninguém mais tem precisa ser pesquisado conta dúvidas de que a pesquisa com uma pequena quantidade científica está relacionada com de pessoas a pesquisar. desenvolvimento social. Considerando que o Brasil é um país do Terceiro Mundo, com grande quantidade de problemas e enormes dificuldades sociais, é muito simples a conclusão de que tem muito a pesquisar para resolver esses problemas e dificuldades. A grande quantidade do que precisa ser pesquisado, porém, conta com uma pequena - muito pequena! - quantidade de pessoas a pesquisar. Isso traz certas implicações para os pesquisadores, coletivamente, e para cada um, individualmente.

Escolher a atividade de pes- Nesse contexto, especificamenquisar e escolher o objeto-alvo te, o que pesquisar não é mais dessa atividade é uma respon- uma opção que o indivíduo faz sabilidade coletiva de todos os porque acha que é distinto dos cientistas do País.

demais, diferente dos outros ou porque vai ter os seus prazeres, satisfações e sucessos particulares. É uma atividade que tem um compromisso muito sério; que tem uma responsabilidade social muito grande. E se nós, cientistas, queremos realmente fazer alguma coisa que sirva à Ciência e à população deste País, temos que assumir esse compromisso e essa responsabilidade. Um compromisso e uma responsabilidade de toda a comunidade científica. Escolher a atividade de pesquisar e escolher o objeto-alvo dessa atividade são compromisso e responsabilidade coletiva de todos os cientistas do País.

As opções pela pesquisa e as es- As opções pela pesquisa e as colhas do que pesquisar devem escolhas do que pesquisar não ser feitas como uma opção de são feitas, ou não devem ser serviço.E devem ocorrer assim feitas, porque os cientistas são porque a população precisa diferentes do resto da populade ajuda.

ção. Elas devem ser realizadas como uma opção de serviço. Elas devem ocorrer assim porque a população precisa de ajuda. Inclusive, porque a população precisa ser auxiliada para poder acompanhar os cientistas e estar junto com eles. E essa é uma tarefa enorme e desafiadora que o cientista tem neste País: ele não pode continuar a falar sozinho ou para seus pares, ele precisa aprender a falar também para as pessoas dos mais diferentes segmentos da população.

Ainda falta a noção de que Não podemos mais considerar Ciência e Tecnologia são dois que, fazendo reuniões cientídos ingredientes que poderão ficas, estamos progredindo em ajudar a superar muitos pro- Ciência. Talvez estejamos em blemas de desenvolvimento parte, uma vez que esse é um do País.

dos aspectos ou momentos do trabalho científico, mas não estamos fazendo ainda o que é necessário e o que precisamos realizar para fazer Ciência no Brasil. Falta ainda, para o País e para grande parte dos pesquisadores, uma percepção fundamental: é imprescindível que aqueles que já se dedicam à pesquisa, junto com os que procuram encontrar oportunidades e condições para pesquisar, tenham claro e sempre presente que Ciência e Tecnologia são dois dos ingredientes que 
poderão ajudar a superar muitos problemas de desenvolvimento do País.

Para fazer Ciência também é Nessa perspectiva, para connecessário que os cientistas do ceber e trabalhar com Ciência País dominem o conhecimento e Tecnologia, os cientistas existente no mundo. brasileiros precisam "dominar o conhecimento" existente. E esse é um desafio para cada cientista: aprender o que existe já conhecido (e conhecido da melhor forma!). O conhecimento existente no mundo, pelo menos na área em que cada cientista atua e em áreas afins, é fundamental para o desenvolvimento como Ciência e como sociedade. Não apenas o conhecimento científico como também o conhecimento produzido por outros processos (ou maneiras) de conhecer. Todos são contribuições que precisam ser conhecidas. Sem "dominar o conhecimento" existente, não superaremos as condições em que vivemos. E isso constitui um desafio e uma responsabilidade muito grandes para quem quer ser cientista neste País: estudar sempre, muito e de tudo que possa relacionar-se com a área em que trabalha.

O conhecimento não se reduza A disposição dos alunos, por uma "prateleira de supermer- exemplo, principalmente dacado", nem às contribuições queles que começam a estudar de cada cientista, ao longo da Psicologia, não pode ser a de história, as "mercadorias" a es- que "esperam isto", "esperam colher ou descartar sem exame aquilo", "não gostam disso", e avaliação cuidadosos. "não querem aquilo". O aluno precisa ser uma pessoa com participação ativa, com a visão de que ele precisa dominar o conhecimento existente porque é disso que depende o desenvolvimento do País onde ele está. É uma finalidade que não tem nada do egoísmo de interesses ou preferências pessoais e, sim, - é preciso insistir - muito de desafio e responsabilidade social. O conhecimento não se reduz a uma "prateleira de supermercado", nem às contribuições de cada cientista ao longo da história, a "mercadorias" para escolher ou descartar sem exame e avaliação cuidadosos.

Como cientistas, precisamos "Dominar" o conhecimento dominar o conhecimento exis- existente é uma finalidade tente, independentemente de importante também para os onde esteja sendo produzido ou cientistas porque não somos de qual seja sua origem. os únicos a produzir o conhecimento - em muitos casos nem sequer produzimos algum conhecimento ou não produzimos a quantidade da qual precisamos. Até para superar as nossas limitações de produção e para termos uma base e localização na empresa social que representa a atividade científica, precisamos "dominar o conhecimento" existente, independentemente de onde estiver sendo produzido ou de qual seja sua origem.

"Dominar" o conhecimento AgrandetarefadaUniversidade existente (alguns diriam é a de produzir o conhecimento "apropriar-se do conhecie torná-lo acessível a todos; por mento") e tornar esse conheisso, debater a pesquisa obriga cimento acessível à sociedaa debater a Universidade. inclusive, uma agência definida para realizá-la: a Universidade. E essa pode ser a grande tarefa dessa instituição. É por isso que discutir a pesquisa em Psicologia obriga a discutir a Universidade. Ela é o lugar - e, em certo sentido, a "frestinha" que existe - para fazer pesquisa. E não podemos perder esse lugar, essa oportunidade, essa "frestinha" que ainda resta para desenvolver o conhecimento. Mesmo nos países desenvolvidos, onde as empresas fazem pesquisa e onde existem muitos institutos de pesquisa, a grande parte da produção de conhecimento é feita nas universidades ou com a colaboração e participação delas.

Os procedimentos pelos quais Quando os cientistas reivinfazemos a Universidade são dicam recursos, é importanparte dos problemas de depen- te lembrar que o dinheiro dência dos países do Terceiro reivindicado para fazer $\mathrm{Ci}$ Mundo. É importante examinar ência é um dinheiro do povo. a Universidade como parte do Investir esse dinheiro adeproblema da construção da quadamente é dever do GoCiência por que é nela que se verno e é uma responsabilirealiza a limitada pesquisa que dade coletiva. A Universidaexiste e onde são formados os de, como agência social, é cientistas do País. uma parte fundamental e é um dos problemas - talvez pela maneira como procede - relacionados à dependência dos países do Terceiro Mundo. Temos uma Universidade que incomoda a todo mundo, que apresenta uma grande quantidade de problemas. E problemas que apenas estamos aprendendo a diagnosticar, e ainda estamos longe de caracterizar, sem falar na identificação de seus determinantes. E esse é um diagnóstico, uma caracterização e uma identificação necessários que precisam da participação do pesquisador que atua no País. Isso é importante porque é na Universidade que se realiza a pesquisa que existe e por que é nela que são formados os cientistas que trabalharão no País.

As universidades do País apro- Participar da discussão sobre ximam-se de uma "anulação" a Universidade não pode lina medida em que, aos poucos, mitar-se a dizer aquilo que estão lhes tirando (ou extin- ela tem de ruim. Apontar guindo) tudo e reduzindo-as a defeitos, deficiências e prouma instituição, inútil, inócua, blemas têm sido no que mais improdutiva, inexistente para a permanecemos e emperramaioria das pessoas. mos no País. Isso é o que faz, inclusive, com que, se alguém ameaçar "fechar as universidades", não aconteça muita coisa como reação. E isso não é apenas uma metáfora. As universidades do País aproximam-se disso porque aos poucos estão lhes tirando tudo, reduzindo-as a uma instituição inútil, inócua, improdutiva, inexistente, "fechada". E sem uma Universidade que mereça esse nome, a Ciência e a pesquisa ficam sem a sua única base possível para, efetivamente, integrar-se à sociedade. Essa parece ser a tendência que existe nos últimos anos no Brasil. Estamos, nós mesmos, participando da extinção da Universidade necessária para o País. 
Mais do que ressaltar os defei- Um dos problemas para o tos e limitações da Universidade desenvolvimento da pesquisa existentes, precisamos propor em Psicologia (do conhecio que deve caracterizá-la, de mento sobre esse tipo de fenôforma a mais pessoas poderem meno) é a necessidade da agir de forma a construir a existência de uma instituição Universidade necessária e não cuja natureza, características, apenas acabar com a que não organização e estrutura sejam está satisfazendo.

adequadas para a construção do conhecimento. Isso não significa manter a Universidade com as características que tem hoje, mas construir uma outra com características necessárias, próprias, que interessa para realizar sua responsabilidade social. A Universidade precisa ser mantida, mas também precisa ser examinada, discutida, estudada, avaliada de maneira apropriada. Com isso será possível, mais do que ressaltar seus defeitos e limitações, propor o que precisa caracterizá-la, de forma a aumentar a probabilidade de mais pessoas agirem de forma a construir a universidade necessária e não apenas acabar com aquela que não está sendo satisfatória.

Não basta, na Universidade, fa- Hoje, a luta ainda é pela mazer pesquisa como um procedi- nutenção de uma Universidamento de ensino ou para man- de. E de uma Universidade ter imagem diante do público Pública porque até agora, no que interessa como clientela. A País, são poucas as universiUniversidade precisa produzir dades "particulares" que não o conhecimento como matéria foram reduzidas a "escolas" e prima para o ensino e para a que ainda participam da proconstrução da Sociedade. dução de conhecimento científico no Brasil. Em geral, o interesse é outro que não a produção do conhecimento necessário para o desenvolvimento científico, tecnológico e social. Umas poucas que fazem pesquisa, distinguem-se das demais, mas, mesmo assim, o interesse predominante raramente é a produção de conhecimento e a sua divulgação para o desenvolvimento do País. Muitas instituições estão enfatizando o uso do conhecimento que existe para "ensinar" diferentes profissões, fazendo umas poucas pesquisas ligadas às atividades de ensino. Em vários casos, há universidades que fazem alguma "pesquisa" voltada para manter o status oficial de universidades ou realizar uma atividade cosmética que contribua para oferecer uma boa imagem ao público que lhe interessa como cliente.

Apesar das limitações, indefini- Apesar das limitações, indefições e dos problemas existentes, nições e dos problemas atuais, a Universidade ainda sobrevive a Universidade ainda existe onde há oportunidades, neces- onde há oportunidades, necessidades e condições para produ- sidades e condições (poucas!) zir conhecimento relevante. para pesquisar e produzir conhecimento relevante. É fundamentalmente por essa razão que os cientistas - incluindo os que estão se formando para isso - têm que participar da discussão e da defesa dessa instituição, sendo na Universidade que são formados os novos quadros de profissionais de nível superior para trabalhar no País, inclusive os novos cientistas e pesquisadores. Isso faz com que os pesquisadores tenham que apresentar uma intensa e competente parti- cipação na construção e defesa da Universidade como fonte e local de condições para realizar a pesquisa que produzirá o conhecimento necessário para o Brasil. Destruir as oportunidades, as condições ou as delimitações de necessidades de produção de conhecimento é também destruir a Universidade e suas perspectivas e, com isso, destruir também as bases da Ciência e da Tecnologia que o País necessita.

Não se trata de apenas "rei- Não se trata de apenas "reivinvindicar coisas" e sim de rei- dicar coisas" e sim de reivinvindicar as condições efetivas dicar para a Universidade as e inquestionavelmente neces- condições necessárias para sárias que ela exerça seu papel que ela exerça seu papel (ou de agência de produção $e$ de responsabilidade social) espedivulgação do conhecimento cífico: agência de produção e importante para o País. divulgação do conhecimento que alicerçará as atividades capazes de produzir condições para o desenvolvimento que a população do País necessita. Como acontece na maioria dos países do chamado Terceiro Mundo, as universidades brasileiras foram transformadas em "escolas profissionalizantes" e isso precisa ser superado. Esclarecer, evidenciar e exigir que a Universidade realize seu papel e reivindicar as condições para isso é uma tarefa bem maior e mais exigente do que apenas reivindicar o que "lhe foi tirado", ou que o que "lhe faz falta".

A atividade da Universidade A Universidade é mais do que não pode reduzir-se a "capa- uma escola para "repassar" citar profissionais, ou o desen- informações, técnicas ou "tevolvimento do conhecimento orias". Ela, mais do que isso, em Psicologia" simplesmente é a base para a produção de não existirá, nem como preo- informações que possam ser cupação. consideradas "conhecimento de valor" para a sociedade. Sem as condições técnicas, financeiras, administrativas e políticas para fazer Ciência na instituição, esse trabalho não existirá, deixando o País de produzir o conhecimento, insumo fundamental para a educação e para o desenvolvimento social. A Psicologia, no Brasil, também é uma das vítimas desse processo de redução das universidades a escolas profissionalizantes. Esse processo "marcou a área a ferro e fogo". Quem conheceu a Psicologia antes da implantação dos cursos de Psicologia sabe o que isso significa. A luta pelos Departamentos em substituição às cátedras individuais e vitalícias, foi um esforço para que os pesquisadores de cada área se reunissem em núcleos produtivos de pesquisa e não em oligarquias administrativas ou burocráticas para continuar controlando o ensino de graduação. Mas, isso parece estar "perdido" até hoje. Poucos ainda lembram do conceito inicial de Departamento que orientou o movimento pela extinção das cátedras.

A Universidade é, antes de tudo, A atividade da Universidade, constituída por núcleos de cien- no caso dos departamentos de tistas organizados em diferentes Psicologia, não pode reduzir-se áreas, elaborando oconhecimen- a formar profissionais, substito para "sustentar" a formação tuindo ou assumindo o papel de pessoas para trabalhar em de coordenações de cursos de diferentes campos de atuação. graduação ou de pós-gradua- 
ção. Ou, então, o desenvolvimento do conhecimento em Psicologia simplesmente não existirá, nem como preocupação. Os departamentos deveriam ser, antes de qualquer outra coisa, a integração de vários núcleos de pesquisa nos quais trabalham cientistas na produção do conhecimento relativo à área do Departamento e na difusão desse conhecimento, o que envolve oferta de professores capacitados para ensinar, em diferentes cursos da Universidade, aquilo que o conhecimento produzido na área mostra ser importante para cada campo de atuação profissional cujos agentes serão capacitados pelos diferentes cursos de cada universidade.

Os profissionais que o País ne- Fomos levados, durante muitos cessita precisam ser profissio- anos, na "onda" de sermos um nais que tenham uma formação país dependente, respondendo científica suficiente para serem a propostas, exigências e necescapazes de produzir conheci- sidades "de fora". A Universimento e atuar na sociedade de dade Brasileira transformou-se maneira coerente com o melhor em uma escola para profissioconhecimento existente. nais que pudessem tornar exequiível ou viável o modelo dominante: um país de consumo, de mercado para outros. Isso não é suficiente. Os profissionais que o País necessita para resolver os seus problemas precisam ser profissionais formados em pesquisa. Devem ser profissionais com um lastro suficiente e adequado de formação científica (capazes de produzir conhecimento) necessária para atuar no País e não o profissional técnico formado de acordo com receitas e modelos que só fazem o País ficar mais apto como mercado para outras nações. É o que faz com que a Universidade e os pesquisadores em cada área sejam alijados dos processos de decisão. As concepções e receitas já vêm prontas e de fora. Isso aconteceu com o ensino de Primeiro Grau, de Segundo Grau, de Terceiro Grau, com a Pesquisa e, agora, nos últimos anos, com a Pós-Graduação. Não há novidade; só que não é mais possível continuar a carregar esse fardo. Não parece aceitável ver a extinção de muitas condições criadas para responder a necessidades do País, sendo substituídas por rotinas de atividades consagradas pela inércia e pelo hábito dos que já aprenderam a realizar essas atividades sob as condições existentes hoje. A gênese de muito do que a Ciência conseguiu nos dias atuais está em algumas décadas antes e nós ignoramos isso. Sem história não faremos Ciência. Pelo menos Ciência digna desse nome.

A Universidade precisa ter in- A única esperança que parece terlocutores na população tanto restar é de um movimento que quanto precisa têlos entre comece na Universidade. É a aqueles que ocupam os cargos própria instituição que precisa de representação política. dizer "a que vem", qual sua proposta, que identidade quer ter. Ela, porém, não pode ficar falando sozinha. Precisa ter interlocutores. Precisa ter interlocutores na população tanto quanto precisa tê-los entre aqueles que ocupam os cargos de representação política. É preciso convencer as pessoas que estão no Congresso e nas Assembléias Legislativas de que a Ciência é um empreendimento e um tipo de atividade muito importantes para o País. É preciso falar e discutir sobre isso até demonstrar e convencer tanto os agentes governamentais quanto nossos próprios colegas e administradores institucionais e a população do País. Em muitos casos, nem sequer consideramos os próprios alunos como interlocutores. Nós os reduzimos a "simples ouvintes" para registrar de alguma maneira o que lhes apresentamos como informação e que, com freqüência, confundimos com "conhecimento".

Se o País perder a Universidade Preservar a Universidade como pública que tem, por deteriora- instituição e mudá-la como ção, má administração, ou por organização são duas grandes reduzi-la a um mero papel de aspirações da comunidade escola profissional, haverá um científica. E essas são, tamatraso científico e social muito bém, duas tarefas muito sérias. grande.

Se o País perder a Universidade pública que tem, por deterioração, má administração, ou por reduzi-la a um mero papel de escola profissionalizante, haverá um atraso científico e social muito grande, talvez irrecuperável. O trabalho que lhe cabe fazer não será feito por outro tipo de instituição e isso não pode continuar a ser escamoteado do País, dos estudantes e até dos próprios cientistas e pesquisadores.

O que precisa ser recuperado Uma outra aspiração - e reina Universidade é muito e é tão vindicação - que faz a comuimportante quanto o que ainda nidade científica (que também falta construir.

vive em um país do Terceiro Mundo) é a existência de verbas públicas adequadas para o financiamento da pesquisa científica. Reivindicar é uma expressão bondosa. Mais claramente, ela precisa gritar, esbravejar, lutar para conseguir um mínimo em relação ao que seria necessário para desenvolver alguma pesquisa de valor no País. O que temos para recuperar do que já foi perdido é muito e é tão importante quanto o que nos falta construir.

Núcleos de pesquisa que exis- Nos últimos 20 anos, as verbas tiam se transformaram, dete- públicas para pesquisa foram rioraram ou desapareceram. reduzidas a um terço do que O País parou ou interrompeu eram. Isso significa que, à memuito da produção de conhe- dida que os problemas sociais cimento que apoiaria a cons- e as necessidades do País se trução da tecnologia necessária agravaram, o investimento em para superar seus problemas. pesquisa foi brutalmente reduzido em relação ao que era há 20 anos. O que significou isso para o País? Significou - e significa-que iniciativas de núcleos de pesquisa que existiam se transformaram, deterioraram e até desapareceram. Significa que o país parou a produção de conhecimento que possibilitaria a construção de tecnologia necessária para superar seus problemas. E ainda continuam existindo procedimentos e concepções, em várias instâncias, promovendo a extinção de núcleos de pesquisa e de departamentos (conjuntos de núcleos por área do conhecimento), nos quais esses núcleos deveriam estar sendo uma "solução" para a "crise" da Universidade.

Em 1940, o Brasil era um país Em 1940, o Brasil era um país que produzia tecnologia. Hoje, que produzia tecnologia. Quasabe-se quase nada sobre oque renta e poucos anos depois, ele produzia. $O$ que presencia- sabe-se quase nada sobre o mos no faz ficar espantados, que ele produzia. Em muitas incrédulos e desanimados. áreas de conhecimento e em muitos setores das universida- 
des nem sequer sabe-se como fazer para produzir a tecnologia necessária para desenvolver o País. Hoje o Brasil "compra tecnologia" e "adota informações"; ele consome o que outros países produzem. Há um engodo nisso tudo, nessa conversa de "transferência de tecnologia", como muitos nomeiam tal tipo de "estratégia" ou "procedimento". Isso é muito grave e exige atenção. Afinal de contas, se o País compra tecnologia, não precisamos produzi-la, não precisamos construir conhecimento para fazer isso.

É importante, como cientis- Nesse sentido, a universidade tas e pesquisadores, reagir e poderia ser apenas uma escola, participar da construção e das os departamentos poderiam reivindicações sobre nossa reduzir-se a meras agências de própria produção de conheci- administração ou burocracia mento e tecnologia, por meio do ensino. Não é o que precide uma universidade íntegra e samos. Nem o que queremos. competente. Mas, são essas concepções, essas maneiras de entender e agir quanto ao conhecimento científico, à pesquisa e à Universidade que levaram à deterioração sistemática dessas atividades, desses recursos e desse patrimônio do País. Até o ponto que hoje presenciamos todos, entre espantados, incrédulos e desanimados. É importante, como cientistas e pesquisadores, reagir e participar da construção e das reivindicações do que é fundamental: nossa própria produção de conhecimento e de tecnologia, por meio de uma universidade íntegra e competente e com os recursos necessários para fazer isso.

Quem decide o que é relevante Existe, "pró-forma" nesta pesquisar e quais recursos República, um orçamento de devem ser alocados para cada Ciência e Tecnologia. É “prótipo de pesquisa necessária forma" porque sabemos quase para o País? nada sobre o que ele significa. Embora o CNPq até publique dados sobre isso, não é conhecida a proposta orçamentária para Ciência e Tecnologia no País. Muito menos se conhece sobre sua execução orçamentária. A pouca "transparência", a falta de acesso e a ausência de participação dos cientistas e Universidades na elaboração do orçamento de Ciência e Tecnologia são problemas muito sérios. Esse orçamento delimita e define muito da atividade científica no País. Como fazer Ciência sem ter possibilidade de sequer conhecer com clareza como se decide o que vai ser investido nisso? Essa é uma decisão só técnica? Só política? Os cientistas não devem participar? Quem decide (e quem deve fazê-lo?) o que é relevante pesquisar e quais recursos devem ser alocados para cada tipo de pesquisa necessária?

A integração das múltiplas agên- A comunidade científica bracias envolvidas na realização e sileira tem feito propostas ao administração da produção de Governo e, em geral, não tem Ciência e Tecnologia, incluindo sido atendida. Um exemplo a participação das universidades dessas propostas está em uma e sociedades científicas é funda- regra muito simples que podemental para o País desenvolver a ria mudar a direção da tendênCiência e a Tecnologia que aten- cia de diminuição constante de da às necessidades da população verbas para a pesquisa no País. que o constitui.

A comunidade científica pro- pôs ao governo que os cientistas participassem das decisões nas agências responsáveis pelo apoio à Ciência e à Tecnologia. Os cientistas consideram que a atual organização do Sistema de Ciência e Tecnologia Nacional tem muitos defeitos. Não parece adequado para o desenvolvimento que o FINEP faça algumas coisas, o CNPq outras, às vezes funcionando como empresas (ou como empresários?). As fundações estaduais fazendo outras coisas e assim por diante. A integração dessas agências em um sistema coerente com uma política bem definida de apoio à Ciência e à Tecnologia, incluindo a participação das universidades e sociedades científicas, é fundamental para o País desenvolver a Ciência e a Tecnologia da qual necessita, que atenda às necessidades de sua população. Aliás, é preciso não esquecer que as fundações estaduais (de amparo à Ciência e à Tecnologia) precisam existir e participar disso também. Por enquanto, ainda não temos fundações estaduais em quantidade e com características adequadas como a FAPESP, por exemplo, conseguiu ter no Estado de São Paulo. Essa é uma reivindicação que os pesquisadores de cada Estado podem fazer: insistir nas assembléias legislativas que se formem fundações estaduais e que se destine uma percentagem do orçamento do Estado para esse tipo de trabalho.

Os valores destinados e efeti- Com essas condições, as verbas vamente alocados e acessiveis federais e estaduais poderiam para os pesquisadores produ- constituir uma condição para zirem Ciência e Tecnologia o desenvolvimento de Ciência oscilam ao gosto dos gover- e Tecnologia. O que existe nantes ou por fatos emergen- hoje, infelizmente, nem sabeciais e não por orientação de mos quanto é. O que se conheuma política definida para o ce é que o que vai para as desenvolvimento de Ciência $e$ pesquisas, não chega a um Tecnologia no País. terço do que foi destinado. Não adianta o Governo, o Presidente da República ou o Ministro dizer que há milhões ou bilhões de reais para a Ciência e Tecnologia. O que de fato acontece é que esses valores oscilam ao gosto dos governantes ou de fatos emergenciais e não por uma política definida para o setor. Em um ano existe e em outros desaparece a verba necessária. Ou é alocada de forma inadequada em relação às prioridades do País, atendendo a "demandas" ou "lobbies" não facilmente identificáveis.

Por que não integrar os múl- Arrisco afirmar que não há tiplos institutos e agências clareza também sobre "para públicas de Ciência e Tecno- onde as verbas estão indo..." logia em um sistema com a Há casos em que não é muito participação da comunidade fácil entender as razões de científica nas decisões sobre o algumas proporções de verque seja importante pesquisar bas. Sabemos, por exemplo, no País?

que a EMBRAPA - Empresa Brasileira de Pesquisa Agropecuária - tem (embora também esteja diminuindo progressivamente) um orçamento maior que o do CNPq. E este é o Conselho Nacional de Desenvolvimento Científico e Tecnológico para todas as áreas em todo o País. Não quer dizer que a EMBRAPA não faça um trabalho importante. Pelo contrário, ele é extremamente necessário para o País. Mas, por que essa diferença? Por que não integrá-la em um sistema com 
a participação da comunidade científica nas decisões? A EMBRAPA não faz parte de um sistema de desenvolvimento de Ciência e Tecnologia para o País? Há exemplos muito bons de como é possível administrar os Recursos de Ciência e Tecnologia para o país. A FAPESP, na própria legislação que a criou, tem definido que a verba para administração não pode ultrapassar 5\% de seu orçamento. Em agências federais há casos em que só o pagamento de pessoal administrativo ultrapassa de $30 \%$ a $60 \%$ do orçamento das agências. No primeiro exemplo, a maior parte da verba vai, de fato, para a pesquisa. No segundo caso é quase toda gasta com a administração. Por essas e por outras razões é grave a pouca participação da comunidade científica nas decisões dessas agências. O pedido de participação feito ao governo até agora foi considerado ingênuo e não foi atendido nos termos em que foi apresentado.

Se a Psicologia, nas universida- Muitos podem dizer que essas des, ficar fora das discussões $e$ reivindicações caracterizam deliberações sobre os recursos apenas um trabalho de "ativispara fazer, para direcionar ou tas políticos". É, porém, uma incentivar a pesquisa, elaficará tarefa de todo cientista, de à margem da própria ciência e qualquer pesquisador. Entecnologia feitas no País. $\quad$ quanto a Psicologia ficar fora das discussões e deliberações sobre os recursos para fazer, para direcionar ou incentivar a pesquisa em Psicologia ela ficará à margem das próprias Ciência e Tecnologia que serão feitas no País. Ficará fora porque não participa. Ficará fora porque tem o "defeito" de ser "Ciências Humanas e Sociais" que, em geral, não são consideradas prioridades quando se trata de Ciência e Tecnologia.

A transformação do serviço Considerando a Universidade público, das universidades, em como agência de produção de empregos sem caracterização Ciência e Tecnologia, o CNPq, ou identidade faz com que a há algum tempo, firmou um instituição deixe de realizar compromisso com a comuniciência e tecnologia, mas man- dade científica: não criar mais tém um orçamento pesado $e$ institutos de pesquisa fora das dois tipos de indigência graves: universidades. Em geral esses profissional, por má produção e institutos são organizações social, por baixos salários. públicas com muito peso na parte de pessoal e o trabalho que fazem, com as devidas condições, recursos e administração pode ser feito nas universidades. Aliás, também as universidades, sem cuidados desse tipo, podem ficar prejudicadas na realização de sua responsabilidade em relação à produção de Ciência e Tecnologia. Na década de 1980 houve um exemplo triste do que tudo isso pode significar. A grande quantidade de funcionários mal pagos nas universidades os está tornando uma grande quantidade de "escravos improdutivos". Grande parte dos funcionários da Universidade de São Paulo (USP), por exemplo, moraram em favelas por um bom tempo. A transformação do serviço público, das universidades no caso, em empregos sem maior caracterização ou identidade faz com que esse tipo de instituição deixe de realizar Ciência e Tecnologia, mas mantenha um orçamento pesado e dois graves tipos de indigência: profissional, por má produção, e social, por baixos salários.
Multiplicação de atividades, É por isso que se torna cada agências, instâncias de poder vez mais necessário estabelee pulverização de recursos cer um sistema, com regras em condições de apoio sem bem definidas coletivamente, um sistema articulado que para as agências responsáveis dê orientação e articulação a pela Ciência e Tecnologia no tudo isso é contribuir para o País. Em caso contrário, cada empobrecimento da Ciência e agência, cada grupo de pesquida Universidade, o que inclui sadores, cada instituição ou muito do que ainda é preciso cada sociedade científica irá fazer em Psicologia. criar as suas revistas, realizar os seus congressos, ter os seus instrumentos, os seus funcionários... Isso poderá ser apenas muita gente fazendo ou repetindo as mesmas atividades, esforços, recursos. Desperdiçando, duplicando e fazendo desnecessariamente e prejudicialmente o que poderia ser feito de outra forma. Teremos, em pouco tempo, uma proliferação de tudo isso sem constituir uma integração que dê identidade, direção e coesão ao trabalho de produção de Ciência e Tecnologia no País. A Psicologia parece ser um caso típico de proliferação de atividades e organizações cada vez mais desligadas umas das outras.

Qual o sistema e quais os seus Hoje, há uma "Secretaria da componentes que precisamos Ciência e Tecnologia" no para o desenvolvimento da País ${ }^{2}$. O que cabe a essa "SeCiência, da Tecnologia e do cretaria"? Ela deve ou não Ensino Superior que o País fazer a integração das agênnecessita? cias que produzem Ciência e Tecnologia? Como e onde ficam as Universidades? No Ministério da Educação? Na Secretaria de Ciência e Tecnologia. Em ambos? Vão ser reduzidas a escolas? A Secretaria de Ciência e Tecnologia vai ignorar os departamentos nas universidades como unidades-base da produção de conhecimento no Brasil? Vai criar seus próprios instrumentos e instituições? Quem vai coordenar os esforços existentes, capacidades disponíveis e instituições ou agências já existentes? Como isso será feito? Vamos alocar tudo isso na Secretaria da Ciência e Tecnologia? E cada um vai administrar o que? Vai integrar ou articular o que? Qual o sistema que precisamos para o desenvolvimento da Ciência, da Tecnologia e do Ensino Superior que o País necessita?

Sem debate, reivindicação $e$ Os pesquisadores precisam organização dos cientistas isso debater essas questões e partudo permanecerá distante e ticipar das decisões a esse parecerá irreal ou impossível. respeito. Criar um sistema para tudo isso ocorrer e participar ativamente dele é definir instâncias de poder e instrumentos para seu exercício. É por essa razão que vai sendo feita muita coisa para, exatamente, "tomar esse poder" ou, como é dito cada vez mais

2 Quando ocorreu o debate em que professora Carolina fêz essa exposição, não havia ainda um Ministério da Ciência e Tecnologia que, mais tarde, viria a existir sucedendo a Secretaria da Ciência e Tecnologia criada pelo governo, como resposta e uma forte e constante reivindicação da comunidade científica, em especial da SBPC, ao longo de vários anos. Algo parecido aconteceu com as Secretarias Estaduais de Ciência e Tecnologia nos anos que se seguiram à década de 1980. 
natural e freqüentemente, "para ocupar espaços". É importante lembrar que, para tanto, é preciso dinheiro e pode ser o dinheiro da pesquisa que será usado para sustentar a administração e os custos de cada agência criada, cada funcionário contratado, cada momento tirado da pesquisa para atividades administrativas. Por tudo isso a comunidade científica não pode ceder em suas propostas e reivindicações: participação dos cientistas nos órgãos de decisão e um sistema de integração da diversidade de agências e instituições de pesquisa e de apoio à pesquisa. Os cientistas querem decidir junto com todos os ministérios e agências que usam o dinheiro da pesquisa para saber quanto usam e como usam. É basicamente isso. Mas parece que sem maior participação, debate, reivindicação e organização dos cientistas isso tudo permanecerá distante e parecerá sempre irreal ou impossível.

Não basta falar ou reclamar $\mathrm{O}$ que foi examinado não quando o dinheiro do projeto acontece apenas com Ciência não veio, a bolsa não saiu... e Tecnologia. No orçamento É preciso falar e participar para a Educação, quanto diem um nível mais alto da hie- nheiro vai ser, de fato, destirarquia de decisóes e em um nado para isso? A maior momento mais precoce de todo parte dessa verba corre o o processo. risco de ser dispersa por atividades que não resultam em educação ou não a constituem. Essa distribuição de verbas entre ministérios, agências, instituições não pode ser algo feito "à vontade". A comunidade científica - desde os estudantes - precisa conhecer os processos pelos quais são tomadas essas decisões, onde elas são tomadas, desde o FMI, o Banco Mundial ou outras agências, inclusive as nacionais, alheias à realidade social e científica do País. Não basta falar ou reclamar quando o dinheiro do projeto não chegou ou a bolsa não saiu... É preciso participar e falar em um nível mais alto da hierarquia de instâncias de decisão e em um momento mais precoce de todo o processo do que aquele em que já ocorreram prejuízos, atrasos ou descaso.

Os pesquisadores precisam fa- Os pesquisadores brasileiros lar e reivindicar para todas as precisam falar e reivindicar áreas de Ciência e Tecnologia. para todas as áreas de Ciência A Psicologia precisa participar e Tecnologia. A Psicologia dessa reivindicação. Isso éfun- precisa participar dessa reidamental para a Ciência e para vindicação e, ao mesmo tema Psicologia no País. po, da reivindicação de sua parte. Isso é fundamental para a Ciência e para a Psicologia crescerem e contribuírem com o desenvolvimento do País. Sem essa participação há o risco de as agências governamentais "inventarem novidades" para o País. Um exemplo disso foi o "Programa de Apoio para o Desenvolvimento de Ciência e Tecnologia" (PADCT), já bastante conhecido de todos. As áreas que fizeram parte do PADCT foram decididas e escolhidas fora do País. As percentagens de distribuição das verbas para esse Programa já vieram, no início, decididas por agências de fora do Brasil. As reações da comunidade científica alteraram as decisões iniciais. Mas só em parte. A verba desse programa era estimada com proporções: o governo brasileiro pagava dois terços, o Banco Mundial pagava um terço, mas... em equipamento comprado fora do País.

Se não reagirmos e não nos Isso, embora seja um exemplo importarmos, faremos apenas ilustrativo, pode até parecer a Psicologia que ditarem ou caricatural, mas é um risco dirigirem de fora ou burocra- que permanece em maior ticamente, nas agências de amplitude: reproduzir, em poder já consolidadas de acordo Ciência, o modelo econômico com interesses $e$ objetivos que a que, há muitos anos, estapodem não corresponder às mos submetidos. Diante de necessidades do País e de desen- coisas desse tipo, feitas em volvimento da Psicologia. nome da Ciência e da Tecnologia, os cientistas precisam manifestar-se, reivindicar sua participação, dizer o que pensam sobre isso e sobre o que é necessário ser feito no País. Psicologia não está à parte ou imune a essas influências. Mais cedo ou mais tarde, a direção de alguém acontecerá... por interessar ao governo ou para contentar algum grupo de pesquisadores, até do próprio País. Assim como o sistema educacional, a política e a economia do Brasil são "estudados" por agentes externos ao Brasil e por grupos políticos e econômicos diversos, também a Psicologia no País interessa ser "estudada" como um possível meio para interferir no que é feito no País. Assim como é "determinado" o que devemos fazer com a Educação, a Política e a Economia, por meio de vários "tutores" de alguma forma atuantes no País, também em Psicologia acontece isso. E, se não reagirmos e nos impormos, faremos apenas a Psicologia que ditarem ou dirigirem de fora ou burocraticamente, nas agências de poder já consolidadas de acordo com interesses e objetivos que correm um alto risco de não corresponder ao que interessa ao País e ao desenvolvimento do conhecimento em Psicologia.

Grande parte das perguntas Grande parte das perguntas que temos são angustiantes. $\boldsymbol{A}$ que temos e que aparecem Psicologia faz parte disso tudo quando debatemos a pesquie precisa decidir qual destino sa no País são angustiantes. ou direção quer para que pos- Principalmente porque revesa fazer o que é necessário de lam as dificuldades para forma a definir e orientar seu fazer Ciência em um país do desenvolvimento, seu "desti- Terceiro Mundo. Na base de no”, sua contribuição. todas essas angustiantes questões e dessa situação da pesquisa no País está um pressuposto perigoso e destrutivo para o desenvolvimento científico e tecnológico: "para que inventar ou descobrir se há cientistas em outros países mais desenvolvidos e nós podemos comprar deles? Basta comprarmos essa tecnologia e não precisamos investir e gastar com a ciência incipiente que temos". Não parece nem sequer razoável aceitar questões ou afirmações como essas como razão para não investir e dedicar esforços para fazer Ciência e Tecnologia no País e para superar suas atuais condições econômicas, sociais, políticas, educacionais, de saúde etc. A Psicologia faz parte disso tudo e precisa decidir já qual destino ou direção quer para poder fazer o que é necessário e, com isso, definir e orientar seu desenvolvimento, seu "destino", sua contribuição. 
Quem deve decidir que Ciência É possível deixar mais claro e que Tecnologia precisam ser onde agir e o que é possível feitas são aqueles que estão fazer. Tem sido reivindicado envolvidos e conhecem o que já que é necessário haver mais foi feito, o que ainda está sendo bolsas de iniciação científica, feito, o que não está sendo feito, que os valores das bolsas de o que precisa ser feito etc. mestrado e doutorado têm que ser mais altos. Tem havido decisões sobre quais pesquisas devem ser financiadas, sobre que incentivos devem ser dados... Têm sido implementados (pelo governo) programas de pesquisa ou de apoio a pesquisas de certas áreas ou de certos tipos. Quem deve decidir isso? Não devem ser os técnicos do governo, do CNPq, da FINEP ou da FAPESP ou de quaisquer outras fundações. Devem ser as pessoas que trabalham com a produção do conhecimento e da tecnologia em cada área. Devem ser aqueles que estão envolvidos e conhecem o que já foi feito, o que ainda está sendo feito, o que não está sendo feito, o que precisa ser feito etc.

A direção do trabalho precisa A direção do trabalho cientíser orientada sobre a segura fico e tecnológico precisa ser base do conhecimento da reali- orientada sobre a segura base dade social com suas necessida- do conhecimento da realidade des e da área de conhecimento social com suas necessidades como conjunto de atividades e de cada área de conhecimende várias pessoas, incluindo to como conjunto de atividaa produção de conhecimento des (não como erudição ou internacional, também do pas- informação acadêmica de alsado, e em todas as unidades guém ou de alguns) de várias ou núcleos de pesquisa no País, pessoas. Isso inclui a produção mesmo os ainda incipientes ou de conhecimento internacioiniciantes nal, também do passado, e em todas as unidades ou núcleos de pesquisa no País, mesmo os ainda incipientes ou iniciantes. Uma das razões pelas quais é importante a participação dos pesquisadores nas agências de apoio à pesquisa é que eles são os que melhor podem dizer que problemas e que pesquisas, em cada área, são os mais importantes. As várias agências consideram que existe prioridade para certas áreas e para certas pesquisas. E esse conceito - de prioridade - é muito influente nas decisões dessas agências. E, com isso, começam vários problemas: Psicologia, por exemplo, não é prioridade, Ciências Humanas e Ciências Sociais também não são prioridades. $\mathrm{O}$ que é prioridade? Prioridade de que ponto de vista? Prioridade para quem? Para o governo? Para o País? Para o desenvolvimento da Ciência? Para algum grupo? Para as empresas e empresários? Ou para algumas delas ou deles?

É necessário identificar com Parece que, em muitos casos, clareza como essas decisões "prioridade" tem sido "fazer influenciam o trabalho de cada aquelas pesquisas que dão um, como direcionam ou in- informações para a tecnologia terferem com cada pesquisa $e$ que vai ser desenvolvida fora com o conjunto das atividades do Brasil". Isso só leva a uma científicas e suas conseqüên- destruição do desenvolvimencias para o Brasil. to científico e tecnológico do próprio País. Isso só faz existir grupos de pesquisadores isolados a produzir pesquisa que não é necessariamente útil ou importante para o Brasil. E, em relação a isso, não basta lutar ou reclamar. É preciso identificar com clareza como essas decisões influenciam o trabalho de cada um, como direcionam cada pesquisa ou como interferem com elas e com o conjunto das atividades científicas e suas conseqüências para o País. É preciso identificar com clareza a manipulação do dinheiro da Ciência, as agências valorizadas e as agências que são abandonadas (como a Universidade, por exemplo) ou deterioram enquanto outras são criadas, consumindo ainda mais recursos.

A Universidade é inventiva, A Universidade Brasileira tem criadora mas o resultado disso, muitos aspectos de inventivifica nas gavetas, vai para fora, dade. Ela produz conhecimenperde-se, morre...

to novo, original. Embora seja ainda muito pouco em relação às suas possibilidades, ela é inventiva e criadora em relação à produção de conhecimento. O resultado dessa inventividade, porém, não chega até o público, até a população. Ela fica nas gavetas, vai para fora, perde-se, morre... Quando há uma pesquisa relevante para o País, as condições existentes ainda tornam seus resultados inacessíveis a quem necessita do conhecimento que foi produzido por meio dela.

Entre o desenvolvimento do Entre o desenvolvimento do conhecimento científico na conhecimento científico na Universidade e a situação da Universidade e a situação da população há uma grande população há um grande hiato. lacuna.

Quanto mais esse conhecimento se aproxima de ser transformado em tecnologia, maior é o hiato em relação à situação da população. Nesse sentido, a invenção não se torna uma inovação. Os resultados, os produtos dos estudos feitos na Universidade, dificilmente ultrapassam as fronteiras da própria universidade. O conhecimento pode até ser disponível, mas difícil e raramente se torna acessível e, muito menos ainda, útil à população.

Onde está a pesquisa em Psico- Quando João Cláudio Todologia no Brasil? $\boldsymbol{O}$ que é feito rov* perguntou "onde está a com essa pesquisa? Quanto é pesquisa em Psicologia no publicado do que é feito pelos Brasil? O que é feito com essa pesquisadores? Quanto do que pesquisa? Quanto é publicado é descoberto se torna acessivel do que é feito pelos pesquisaa quem? dores?" ele indicou um problema muito sério que prejudica muito ao País: a produção científica e tecnológica não é acessível. Mesmo para apoiar outros trabalhos científicos no País, o conhecimento parece pouco acessível. Há pouco tempo, dois autores brasileiros encontraram que mais de $95 \%$ das referências da revista Psicologia são estrangeiras. Vale insistir na pergunta de João Cláudio Todorov: onde está a pesquisa em Psicologia no Brasil? Talvez as condições existentes constituam uma parte daquilo que leva muitos pesquisadores a publicar no exterior. Pelo menos eles encontram interlocutores, alguém que "ouve”, alguém que fala, dá feedback, usa o conhecimento... Mas será que isso resolve, não o problema do indivíduo ter interlocutores, mas o uso do conhecimento científico na sociedade? Essa é uma pergunta necessária porque cada vez mais temos cientistas descobrin- 
do, propondo soluções para problemas, obtendo resultados impressionantes em pesquisas nacionais e... alguém se apropria disso! Alguém as conhece, leva embora, leva para fora, ou, se não lhe for conveniente, procura encobrir ou manter desconhecido (*As questões foram apresentadas na exposição de João Cláudio Todorov também na mesa redonda sobre "A pesquisa no Brasil; problemas e soluções" realizada na XIV Reunião Anual de Psicologia da Sociedade de Psicologia de Ribeirão Preto -SP, em outubro de 1984).

Feito e relatado para as ban- $\mathrm{O}$ que estamos fazendo com cas examinadoras ou para a as descobertas de nossas prócomunidade especializada, $o$ prias pesquisas? Porque muito trabalho do cientista está en- do que foi descoberto, do que cerrado? está sendo descoberto ou já é conhecido não é utilizado no

País? Porque ainda faz parte tão forte do sistema administrativo do País as "engrenagens" da "política científica e tecnológica" que o governo tem, principalmente em relação aos compromissos internacionais, incluindo manter a população como "mercado consumidor" para outros países ou para grandes empresas. O trabalho de produção de Ciência e Tecnologia fica, no Brasil, sempre incompleto. Feito, relatado (para as bancas examinadoras ou para a comunidade especializada) o trabalho do cientista está encerrado?

Ainda somos incapazes de ver Ainda não é discutido nem que, quando alguém chega a administrado o produto da um resultado, a um produto em atividade científica que tamqualquer trabalho científico, bém precisa ser entendido e esse produto dever ser tratado incluído como parte inteem termos políticos. A quem grante da atividade do cienserve? Como e a quem deve tista. Ainda somos incapazes tornar-se acessivel? de ver que, quando alguém chega a um resultado, a um produto em um trabalho científico, na Universidade, esse produto deve ser considerado também em termos políticos. A quem serve? Como e a quem pode ou deve tornar-se acessível? São perguntas políticas, mas precisam ser enfrentadas pelos cientistas que devem ser também responsáveis pela implementação das respostas a elas. As providências que as responderiam são partes integrantes do trabalho de fazer Ciência.

Não há uma política de ad- Insistindo mais uma vez: ministração da utilização do embora tenhamos muita inconhecimento científico fora ventividade em Ciência e da Universidade. Utilização por Tecnologia nas universidades, aqueles que, com seu trabalho, é preciso também uma polítiproduzem a riqueza que susten- ca de inovação no uso e na ta o trabalho dos cientistas. administração do produto da atividade científica. Nas uni-

versidades existem muitas idéias e pesquisas de ótima qualidade. Mas, no momento em que elas precisam sair da universidade, sair da instituição, aparecem várias dificuldades. Essas dificuldades são reais, mas são criadas pelos que trabalham na própria Universidade. Ainda não temos clareza sobre os problemas e limitações que os cientistas e os administradores têm pra realizar essa etapa do trabalho científico e tecnológico. Não são dificuldades inerentes ao trabalho científico ou à população. $\mathrm{O}$ que não há é uma política de administração da utilização do conhecimento científico fora da Universidade, utilização por aqueles que, com seu trabalho, produzem a riqueza que sustenta, que paga o trabalho dos cientistas.

Ciência não é uma atividade A Ciência que temos e que individual; é um empreen- fazemos ainda precisa encondimento coletivo. Por isso trar soluções para uma grande exige decisões coletivas e parte de seus problemas. É políticas que orientem as ati- necessário que todos particividades individuais. Decisões pem das atividades e decisões políticas, por sua natureza, que produzirão essas soluções são um tipo de atividade e indicarão esses caminhos, eminentemente coletiva. em todos os níveis. Ciência não é uma atividade individual, é um empreendimento coletivo. Por isso exige decisões coletivas e políticas que orientem as atividades individuais. E decisões políticas, por sua própria natureza, são um tipo de atividade eminentemente coletiva. É nesse sentido que política científica em Psicologia não se fará sem a participação dos cientistas e das universidades do País. Nem se fará sem instrumentos, instituições e atividades que sejam, indubitavelmente, condições apropriadas para que essa participação coletiva seja real, significativa e emancipadora. Não apenas dos cientistas ou da Ciência como instituição, mas da própria população. Uma população que depende desse tipo de trabalho para superar as condições que a impedem de viver com dignidade.

A exposição da professora Carolina Martuscelli Bori é, agora em 2007, apresentada em um contexto social, político e científico e tecnológico muito diferente do ano em que fez a exposição oral (metade da década de 1980). Muito do que professora Carolina afirmava na época fazia parte daquilo pelo qual a cada dia se trabalhava para superar, aperfeiçoar, desenvolver. Quando fazia esse debate não havia no Brasil um Ministério da Ciência e Tecnologia. Apenas uma Secretaria fazia esse papel. Quando, já como decorrência dos esforços dos cientistas, especialmente da SBPC e da força da professora Carolina nessa instituição, durante o governo do Presidente Sarney, criado o Ministério da Ciência e Tecnologia, foi constituído um "Conselho Nacional de Ciência e Tecnologia" que excluía as Universidades. Em poucos dias, a professora Carolina estava com a Direção da SBPC em Brasília, em audiência com a Presidência, reiterando correção disso.

Os tempos eram outros e muito difíceis. Várias providências foram tomadas desde então e até mesmo como decorrência de muito do que professora Carolina Bori nos mostrou naqueles tempos. Muitas dessas providências ainda são parciais. Por exemplo, ainda é recente a criação de Secretarias de Estado da Ciência e Tecnologia e, na maioria dos casos, como consolidação de fundações estaduais ou com funções meramente burocráticas e não de liderança e consolidação de um sistema de desenvolvimento de Ciência, Tecnologia e Ensino Superior para consolidar bases de conhecimento necessárias para o desenvolvimento social. Várias delas foram feitas apenas nos moldes de uma adaptação do que existia, mantendo as velhas estruturas e antigos procedimentos que 
garantem até hoje muitos redutos de poder e uma ainda alta exclusão dos que fazem Ciência. Grande parte dos agentes - cientistas, estudantes, instituições - são tolerados apenas como espectadores (e até como clientes ou pedintes) em muitas circunstâncias. Isso também é visível em congressos que se tornaram muito mais centros de exibição e oportunidades de acompanhar o que acontece do que de debate real do que está sendo feito pelos diferentes grupos de cientistas, pesquisadores ou outros profissionais que procuram pesquisar também no seu exercício profissional.

A própria proliferação de "sociedades científicas" e "congressos de cientistas" ou "de profissionais" aumentou exponencialmente e o debate, que antes já era pouco, tende a ser mais uma confraternização em torno de idéias semelhantes, fechamento entre "iguais" ou "exclusão dos diferentes". Com isso, diminui cada vez mais um sistema articulado de Ciência e Tecnologia que, em governos patrimonialistas e centralizadores, só tenderão a fazer articulações de interesse da manutenção de determinados grupos no poder ou de interesses e controle da participação de quem for conveniente para manter o sistema como interessar aos que ocuparem cargos de poder no País.

As questões, afirmações e provocações de professora Carolina Martuscelli Bori parecem atuais, com as devidas correções nas proporções dos exemplos e dados. Os debates sobre participação, organização, representação da Psicologia ou de qualquer tipo de contribuição para sua construção no País, não devem desconsiderar essas eternas contribuições de professora Carolina. Por essa razão, reiteramos, que lhes apresentamos essa exposição, partilhando a riqueza do exame de professora Carolina com outros psicólogos. Esperamos estar acertando em fazer isso, com as também reiteradas desculpas por, provavelmente, prejudicarmos a riqueza do que seria ouvir as palavras da própria professora Carolina. $\mathrm{O}$ esforço de algumas centenas de horas trabalhando com este texto nunca nos pareceu muito. A tarefa final parece ser a de partilhar tudo isso. Isso nos deixa com a sensação de que cumprimos um dever que temos em relação aos cientistas, psicólogos, estudantes de Psicologia e brasileiros, todos que podem ser beneficiários do conhecimento sobre Psicologia. 